\title{
DE CROCE A VICO: MI PROCESO DE LECTURA
}

\author{
Pio Colonnello \\ (Universidad de Calabria)
}

RESUMEN: Este breve artículo describe el proceso de lectura que me ha conducido al interés por la figura y la obra de G.B. Vico, a partir del magisterio crociano y de la nueva línea de estudios viquianos inaugurada en 1968.

Palabras Clave: Vico, $350^{\circ}$ Aniversario, historicismo, recepción en América Latina, P. Colonnello.

\section{From Croce to Vico: My process of reading}

ABSTRACT: This brief article describes the reading process that arose my interest in the figure and work of G.B. Vico, inspired by Croce's teaching and the new line of Vichian studies inaugurated in 1968.

KEYWORDS: Vico, $350^{\text {th }}$ Anniversary, historicism, reception in Latin America, P. Colonnello.

\section{Da Croce a Vico: il mio processo di lettura}

RIASSUNTO: Questo breve articolo descrive il processo di lettura che mi ha portato all'interesse per la figura e il lavoro di G.B. Vico, ispirato dal magistero crociano e dalla nuova linea di studi vichiani inaugurata nel 1968. Parole Chiave: Vico, $350^{\circ}$ Anniversario, storicismo, ricezione in America Latina, P. Colonnello.

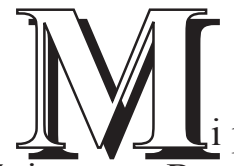

primer encuentro con Vico estuvo propiciado por la lectura de las páginas que Benedetto Croce dedicó al autor de la Scienza nuova. Apasionado lector, desde mis tiempos de instituto superior, de Francesco De Sanctis y de Benedetto Croce, en mi primer año de universidad, tras haber leído el capítulo sobre Vico en la parte histórica de la Estética crociana, quise profundizar en su fundamental monografía de $1911 .{ }^{1}$ Omito la referencia a la viva impresión que suscitó en mí esta obra, para aludir más bien a la tonalidad hermenéutica fundamental que yo capté entonces y que identificaría, enseguida, como un leitmotiv de la interpretación crociana global: la acentuación del perfil intelectual y moral del autor de la Scienza

Este artículo responde a una invitación expresa por parte de la Dirección de la Revista para este volumen especial por el $350^{\circ}$ Aniversario del nacimiento de G. Vico, habiendo superado los criterios de valoración y del proceso de aceptación. 
nuova como el de un pensador austero, «una figura melancólica y seria», toda vez que, según expresión del propio Croce, «jamás se rió»; incluso, «hasta más serio que el rostro de Dante. Y al mismo tiempo nos recuerda los dolores de su vida, en ese desdén contra los fáciles "burlones" que de él y de su Scienza nuova hacían escarnio». ${ }^{2}$

Un juicio ciertamente en línea con la imagen que Croce en otros lugares ha consignado de Vico, tratando sobre su honestidad moral y su incorruptible postura intelectual, soportes firmes de ese heroísmo de pensamiento que permitió al filósofo superar la potencia de lo negativo, siempre presente en su experiencia existencial:

«El heroísmo era, para él, la fuerza virgen y extrapotente, que aparece en los inicios y reaparece en el transcurso de la historia. Él debía sentir esta fuerza en sí mismo, al trabajar por la verdad y al abrir, abatiendo toda suerte de obstáculos, nuevas vías a la ciencia. Por esta fuerza, superadas las inseguridades juveniles, los extravíos, los abatimientos, que a veces lo hicieron caer en un hondo pesimismo individual y cósmico (como se ve en el poema Affetti d'un disperato), pudo ascender hasta la segura profesión de un método científico, que enunció en el $D e$ nostri temporis studiorum ratione». ${ }^{3}$

Omito, obviamente, hacer referencia a los temas fundamentales de la interpretación crociana, considerada la naturaleza personalísima de este escrito; temas y cuestiones en que, sin embargo, tuve ocasión de profundizar, cuando en el año académico 1973/74 obtuve una beca de estudios en el "Istituto Italiano per gli Studi Storici", fundado en Nápoles, en el palacio Filomarino, justamente por Benedetto Croce. ${ }^{4}$

Entre tanto 1968, año del tercer centenario del nacimiento de Vico, marcó un profundo cambio en los estudios viquianos, que tuvo obviamente una fuerte incidencia también sobre mis lecturas. En efecto, en dicho año se publicó el volumen de varios autores, Omaggio a Vico, ${ }^{5}$ que fue seguido por la creación de un importante órgano de investigación y de estudios críticos, el Bollettino del Centro di Studi Vichiani (BCSV), fundado por Pietro Piovani. ${ }^{6}$ Me sumergí, así, en la lectura de los

1. B. Croce, La filosofia di G.B. Vico, Laterza, Bari, 1911; ahora en la edición nacional de las obras, Bibliopolis, Nápoles, 1997.

2. Cfr. B. Croce, La dottrina del riso e dell 'ironia in G.B. Vico, en Studi dedicati a F. Torraca, Nápoles, 1912; reimpreso en Saggio sullo Hegel seguito da altri scritti di storia della filosofia, Laterza, Bari, 1948 ( $4^{\mathrm{a}} \mathrm{ed}$.); ahora en la edición nacional de las obras, Bibliopolis, Nápoles, 2006, p. 278.

3. B. Croce, Intorno alla vita e al carattere di G.B. Vico, en La filosofia di Giambattista Vico, Bibliopolis, Nápoles, 1997, pp. 261-262.

4. Permítaseme una referencia a un dato biográfico: tengo el honor de vivir en este monumental palacio, que fue morada de Benedetto Croce hasta 1952, año de su muerte, y antes acogió en una de sus salas al propio Giambattista Vico, preceptor de los hijos del príncipe Filomarino.

5. AA.VV., Omaggio a Vico, Morano, Nápoles, 1968.

6. El Bollettino del Centro di Studi Vichiani (BCSV) es todavía la importante revista del "Istituto per la Storia del Pensiero Filosofico e Scientifico moderno" (ISPF) del C.N.R., antes del "Centro di Studi Vichiani", con sede en Nápoles. 
números de la revista, y también en los volúmenes de los estudiosos que colaboraban en ella, y seguí con interés la revisión de las categorías historiográficas y hermenéuticas en el campo de los estudios viquianos.

Entre las novedades exegéticas, que me impresionaron en primer lugar, constaté la apuesta por una idea central de la tradición historiográfica sobresaliente en Benedetto Croce y en Fausto Nicolini: la que localizaba en Vico «al siglo decimonónico en germen». La ya datada categoría del "precursorismo" era entonces puesta en cuestión por estudiosos como Pietro Piovani, Fulvio Tessitore, Giuseppe Cacciatore, Giuseppe Cantillo, Enrico Nuzzo, ${ }^{7}$ por citar solo algunos, los cuales, aun reconociendo los méritos de la tradición crociana, intentaban profundizar, más bien, en las conexiones entre Vico y el historicismo posthegeliano, por ejemplo entre Vico y Dilthey y, por otra parte, dar espacio al Vico "menor", al Vico "historiador" y al Vico "joven", con particular atención a los descubrimientos archivísticos, a las "fuentes" de la erudición viquiana, a la cultura del Reino napolitano en el siglo XVII. ${ }^{8}$ Pero no pocos intérpretes y exégetas contemporáneos han compartido después la tesis de un Vico sin Hegel. ${ }^{9}$

No es posible discutir aquí, y ni siquiera simplemente mencionar, por la naturaleza del escrito y por la exigüidad del espacio concedido, todo el cúmulo de reinterpretaciones, de estímulos, de sugerencias, que la nueva línea de estudios ofrecía a las vexatae quaestiones del pensamiento viquiano: desde la interrogación sobre el fundamento no físico del orden físico, no histórico del orden histórico, no moral del orden moral, a la cuestión de si la historia ideal eterna niega o no la historicidad de la historia, al significado de la "providencia" en la obra viquiana, al papel de la memoria, de la fantasía y del ingenio y así sucesivamente; estímulos,

7. P. Piovani, Vico senza Hegel, en AA.VV., Omaggio a Vico, cit., pp. 553-586; ID., «Dieci annate del Bollettino del Centro di Studi Vichiani», BCSV, X (1980), p. 8; F. Tessitore, «Presentazione», BCSV, XVI (1986); ID., «Momenti del vichismo giuridico-politico nella cultura meridionale», BCSV, VI (1976), pp. 76-111; ID., Giovambattista Vico, Istituto Poligrafico dello Stato, 2000; G. CACCiatore-G. CANTILlo, «Materiali su Vico in Germania», BCSV, XI (1981); G. CACCiatore, L'infinito nella storia. Saggi su Vico, Edizioni Scientifiche Italiane, Nápoles, 2010; ID., In dialogo con Vico. Ricerche, note, discussioni, Edizioni di Storia e Letteratura, Roma, 2016; E. Nuzzo, Vico, Vallecchi, 1974; ID., Tra ordine della storia e storicità. Saggio sui saperi della storia in Vico, Edizioni di Storia e Letteratura, Roma, 2002.

8. Para este "programa", cfr. P. PIovanI, «Il Centro di Studi Vichiani», BCSV, I (1971), pp. 5-19. Otra iniciativa de fundamental importancia del Centro fue la edición nacional de las obras viquianas. Cfr. P. PIovanI, «Per l'edizione nazionale di Vico», BCSV, II (1972), p. 8; L'edizione critica di Vico. Bilanci e prospettive, ed. a cargo de G. Cacciatore-A. Stile, Guida, Nápoles, 1997. Cfr. al menos dos importantes ediciones críticas de la Scienza nuova: la de la edición de 1730, editada por P. CRistofolini y M. SANNA, Guida, Nápoles, 2004; y la de 1744, a cargo de P. CRistofolini y M. SanNa, Edizioni di Storia e Letteratura, Roma, 2013.

9. Cfr. V. Vitiello, Vico e la topologia, Cronopio, Nápoles, 2002; ID., Vico. Storia, linguaggio, natura, Edizioni di Storia e Letteratura, Roma, 2008; ID., Vico-Hegel. La memoria e il sacro, La Città del Sole, Nápoles, 2006; cfr. también ID., Intervista immaginaria a G.B. Vico, recogido en el vol. 19 de la Enciclopedia Filosofica Bompiani, Ediciones especiales del Corriere della sera, RSC, Milán, 2010: «Hegel parte de la lógica del "significado", de la palabra significante, es decir, se mueve desde el lenguaje codificado por Aristóteles»; se trata, por el contrario, de interrogarse «sobre el surgir de la palabra significante»; para hacerlo es preciso «transgredir el lenguaje de la lógica, de la ciencia, de la filosofía. El lenguaje de la Scienza nuova "mima" de cualquier modo el lenguaje del mito, repite el gesto». 
sugerencias y reinterpretaciones que tuvieron incisiva influencia en la formación de la generación de estudiosos a la que pertenezco. ${ }^{10}$

Por mi parte, aunque interesado en algunas fecundas pistas hermenéuticas señaladas por la reciente investigación viquiana, en particular en los temas de la pertenencia al cuerpo de las facultades de la mente y de la fantasía y en la relectura del ingenio como «la facultad en la que principalmente resulta visible la estructura integrada del nexo mente-cuerpo», ${ }^{11}$ o en la tesis que considera la Scienza nuova como una «crítica de la crítica del saber», sin embargo, he intentado investigar aspectos menos conocidos de la recepción viquiana: me refiero al interés que suscitó el pensador napolitano en algunas corrientes filosóficas latinoamericanas. Dirigí así mi atención, de manera peculiar, hacia la interpretación viquiana de dos pensadores del denominado "exilio español", refugiados en Méjico tras la derrota republicana en la España franquista: Eugenio Ímaz y Eduardo Nicol.12 El primero, al manifestar interés por Vico, reinterpretó toda la tradición del historicismo como una vía de acceso privilegiada para profundizar en las relaciones entre lo individual y lo universal, entre existencia e historia, entre hecho y valor. En los pliegues de este problema se encuentra la cuestión auténticamente existencial e histórica, que desgarró la conciencia de Ímaz: la cuestión del mal y del dolor individual, más allá de la solución ofrecida a tal problemática por el historicismo de impronta hegeliana. En la conclusión de esta obra, Ímaz observaba que no se trataba

«de superar el historicismo, sino más bien de hacer un buen historicismo que, a fin de cuentas, conciliase la filosofía y la historia, los filósofos y los historiadores, lo universal y lo concreto: un historicismo que curase nuestra conciencia atormentada, estableciendo la unidad de la experiencia humana y haciendo soportable el problema del mal por el poder tranquilo que esta nos dará sobre él. Es el historicismo al que mira nuestro Dilthey, es el historicismo noble, generoso, heroico, de un Croce o de un Dewey».13

Por otra parte, Eduardo Nicol, aunque influido por la tradición historiográfica europea, en particular crociana y nicoliniana, sin embargo, elaboró una original reflexión sobre la historicidad de la razón y sobre la peculiaridad del tiempo histórico en Vico. La idea de la historicidad de la razón está en la fuente tanto de la his-

10. Para estos temas, remito a mi reseña historiográfica «Vico a Napoli negli ultimi venti anni (1968-1988)», en Progresso del Mezzogiorno, a. XIII, n. 1-2, pp. 329-344.

11. G. CACCIATORE, «La facoltà della mente "rintuzzata" dentro il corpo», in Il corpo e le sue facoltà. G.B. Vico, ed. por G. Cacciatore, V. Gessa Kurotschka, M. Sanna, A. Scognamiglio, en Laboratorio dell'ISPF, I, 2005, p. 98. 12. P. Colonnello, Itinerari di filosofia ispanoamericana, Armando, Roma, 2007; «Eduardo Nicol intérprete de Vico», Cuadernos sobre Vico, n. 17-18, 2004-2005, pp. 267-275; ID., «E. Nicol e G.B. Vico», en Vico nelle culture iberiche e lusitane, G. CACCiATORE - M. MartiRano (EDs.), Guida, Nápoles, 2004, pp. 81-94.

13. E. Ímaz, El pensamiento de Dilthey. Evolución y sistema, El Colegio de México, México, 1946, p. 345; Cfr. J.M. SEVILLA, «Vico e l'umanesimo storicista di Eugenio Ímaz», en Vico nelle culture iberiche e lusitane, cit., pp. 31-62. 
toricidad del derecho, como de la historicidad de la filosofía. Antes incluso que Savigny, considerado el fundador de la escuela histórica del derecho, fue Vico quien, en opinión de Nicol, subrayó la función vital e histórica, los orígenes y las formas de evolución del derecho. Respecto a la historicidad de la filosofía, su comprensión del curso histórico en la reconstrucción unitaria de la variedad de hechos y de personalidades del pasado exige una íntima compenetración de la filosofía con su historia. Además, la idea de la historicidad de la filosofía es un concepto que Nicol hizo propio, en la línea que va de Vico a Dilthey y a Ortega. Finalmente, en cuanto al tiempo histórico, al comentar la idea viquiana según la cual la Scienza nuova, atenta al «orden presente de las cosas, impuesto por la Providencia, vendría tal ciencia a ser una Historia Ideal Eterna, sobre la cual discurra en el tiempo la historia de todas las naciones», Nicol se pregunta sobre lo que distingue propiamente al tiempo histórico del tiempo físico-serial, en el cual el orden de la sucesión es unívocamente un orden causal. Del tiempo se subrayan obviamente los trazos cualitativos de la irrepetibilidad del evento, de la originalidad, de la absoluta libertad de la elección, pero, en modo particular, las características del novum y de la indeterminación abierta por la dimensión del futuro. Y es precisamente la orientación hacia el ektasi del porvenir, o más bien la primacía del futuro, lo que remarca la distancia de la temporalidad ordinaria o del tiempo natural, privado de diferenciaciones cualitativas. En síntesis, Nicol interpreta el tiempo histórico en Vico como el tiempo de la libertad y de la "espontaneidad creadora",

«que abre caminos siempre nuevos, y por ello siempre aventurados, en vez de reseguir con seguridad monótona los caminos trazados de antemano por la Providencia o por la naturaleza, y recorridos por todos los pueblos del pasado». ${ }^{14}$

No siendo posible profundizar, en esta sede, en este conjunto de temas, intento volver en otros espacios a la recepción de Vico en América Latina, convencido de ganar la tierra firme de islas menores respecto al inmenso archipiélago del pensamiento viquiano.

[Traducción del italiano por María José Rebollo Espinosa]

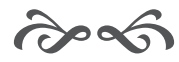

14. Cfr. E. Nicol, Historicismo y existencialismo. La temporalidad del ser y la razón, FCE, México, 1950. Los fragmentos citados de esta obra, traducidos [al italiano] por mí, pertenecen a la reedición de la $3^{\text {a }}$ edición (1989), publicada siempre en la Colección filosófica de Fondo de Cultura Económica. [N.E.: El autor, en su texto original, ha traducido al italiano las citas de Nicol, que aquí ofrecemos en cambio tomadas de la $2^{\mathrm{a}}$ edición corregida del texto en español de Historicismo y existencialismo (1950), vol. IV de Obras de E. Nicol, editado por Editorial Tecnos S.A., Madrid, 1960 ( $2^{\mathrm{a}}$ ed.); citas a p. 73 y p. 74 respectivamente]. 
<smiles>[As]</smiles> 